\title{
BMJ Open The Upper Gastrointestinal Cancer Registry (UGICR): a clinical quality registry to monitor and improve care in upper gastrointestinal cancers
}

Ashika D Maharaj (D) , ${ }^{1}$ Jennifer F Holland, ${ }^{1}$ Ri O Scarborough, ${ }^{1}$ Sue M Evans (D) ${ }^{1}$ Liane J loannou, ${ }^{1}$ Wendy Brown, ${ }^{2}$ Daniel G Croagh (1) , ${ }^{3}$ Charles H C Pilgrim, ${ }^{4}$ James G Kench, ${ }^{5}$ Lara R Lipton, ${ }^{6}$ Trevor Leong, ${ }^{7}$ John J McNeil, ${ }^{1}$ Mehrdad Nikfarjam, ${ }^{8}$ Ahmad Aly, ${ }^{9}$ Paul R Burton, ${ }^{2}$ Paul A Cashin, ${ }^{3}$ Julie Chu, ${ }^{7}$ Cuong P Duong, ${ }^{7}$ Peter Evans, ${ }^{10}$ David Goldstein, ${ }^{11}$ Andrew Haydon, ${ }^{4}$ Michael W Hii, ${ }^{12}$ Brett P F Knowles, ${ }^{13}$ Neil D Merrett, ${ }^{14}$ Michael Michael, ${ }^{7}$ Rachel E Neale, ${ }^{15}$ Jennifer Philip (D) , ${ }^{12}$ Ian W T Porter, ${ }^{16}$ Marty Smith, ${ }^{4}$ John Spillane, ${ }^{7}$ Peter P Tagkalidis, ${ }^{4}$ John R Zalcberg ${ }^{1,4}$

To cite: Maharaj AD, Holland JF, Scarborough RO, et al. The Upper Gastrointestinal Cancer Registry (UGICR): a clinical quality registry to monitor and improve care in upper gastrointestinal cancers. BMJ Open 2019;9:e031434. doi:10.1136/ bmjopen-2019-031434

- Prepublication history for this paper is available online. To view these files, please visit the journal online (http://dx.doi. org/10.1136bmjopen-2019031434).

ADM and JFH contributed equally.

Received 04 May 2019

Revised 26 August 2019

Accepted 02 September 2019

Check for updates

(C) Author(s) (or their employer(s)) 2019. Re-use permitted under CC BY-NC. No commercial re-use. See rights and permissions. Published by BMJ.

For numbered affiliations see end of article.

Correspondence to Professor John R Zalcberg; john.zalcberg@monash.edu

\section{ABSTRACT}

Purpose The Upper Gastrointestinal Cancer Registry (UGICR) was developed to monitor and improve the quality of care provided to patients with upper gastrointestinal cancers in Australia.

Participants It supports four cancer modules: pancreatic, oesophagogastric, biliary and primary liver cancer. The pancreatic cancer (PC) module was the first module to be implemented, with others being established in a staged approach. Individuals are recruited to the registry if they are aged 18 years or older, have received care for their cancer at a participating public/private hospital or private clinic in Australia and do not opt out of participation.

Findings to date The UGICR is governed by a multidisciplinary steering committee that provides clinical governance and oversees clinical working parties. The role of the working parties is to develop quality indicators based on best practice for each registry module, develop the minimum datasets and provide guidance in analysing and reporting of results. Data are captured from existing data sources (population-based cancer incidence registries, pathology databases and hospital-coded data) and manually from clinical records. Data collectors directly enter information into a secure web-based Research Electronic Data Capture (REDCap) data collection platform. The PC module began with a pilot phase, and subsequently, we used a formal modified Delphi consensus process to establish a core set of quality indicators for PC. The second module developed was the oesophagogastric cancer (OGC) module. Results of the 1 year pilot phases for PC and OGC modules are included in this cohort profile. Future plans The UGICR will provide regular reports of risk-adjusted, benchmarked performance on a range of quality indicators that will highlight variations in care and clinical outcomes at a health service level. The registry has also been developed with the view to collect patientreported outcomes (PROs), which will further add to our understanding of the care of patients with these cancers.
Strengths and limitations of this study

- The Upper Gastrointestinal Cancer Registry is the first clinical quality registry (CQR) in Australia, designed to capture information on upper gastrointestinal (UGI) cancers with the aim to improve practice by monitoring and providing benchmarked reports to participating sites.

- We describe the development of a CQR for UGI cancers, including the establishment of governance, recruitment framework, clinical quality indicators, minimum data set, data access policy and reporting structure.

- This registry was developed as per the Australian Commission on Quality and Safety in Health Care's (ACSQHC) Framework for Australian CQRs and follows ACSQHC's Australian Operating Principles for CQRs and can be used as a model for researchers developing CQRs.

- The time-consuming and labour-intensive site governance approval process in Australia is a major limitation for rollout of the registry.

\section{INTRODUCTION}

The five most common upper gastrointestinal (UGI) cancers in Australia are pancreas, oesophagus, stomach, liver (hepatocellular carcinoma) and biliary cancers; the combined incidence is approximately 10000 , and there are around 7500 deaths annually. ${ }^{1}$ The 5 -year relative survival rates of UGI cancers are among the worst of all tumour types: $9.8 \%$ in pancreas; $18.5 \%$ in liver; $20.1 \%$ in biliary; $22 \%$ in oesophagus; and $30.3 \%$ in stomach. ${ }^{1}$ The dismal prognosis of these cancers can be largely attributed to their presentation at an 
advanced disease stage. Additionally, older age is a risk factor for mortality from these tumours, and significant cardiac and respiratory comorbidities may limit treatment options. As a result, only $15 \%$ of pancreas, $43 \%$ of liver, $20 \%$ of oesophagus and $50 \%$ of stomach cancers are potentially resectable at diagnosis. ${ }^{23}$

Resection, with radical lymph node dissection where appropriate, remains the principal potentially curative therapy for all localised UGI cancers. Disease management is almost invariably multimodal and may include chemotherapy and radiotherapy as neoadjuvant, adjuvant or palliative therapy and the provision of optimal supportive care. ${ }^{4-8}$

The aggressive nature of these cancers and the complexity of treatment often decrease health-related quality of life. ${ }^{9}$ Advances in surgical techniques and perioperative care have resulted in operative mortality falling to less than $5 \%$ in major centres. ${ }^{10}$ However, surgery remains a morbid procedure with postoperative complications resulting in prolonged hospital admission, adversely impacting on overall quality of life and the ability to undergo any adjuvant therapies. ${ }^{11}$ In those surviving 1-2years following curative treatment, health-related quality of life generally recovers to baseline. However, there are still major challenges faced by survivors. For those having palliative or supportive therapy only, quality of life frequently deteriorates throughout the disease trajectory. ${ }^{9}$

Local or distant cancer recurrence occurs frequently following resection for all UGI cancers. A third of patients diagnosed with stomach $^{12}$ and half of all patients diagnosed with oesophageal ${ }^{13}$ cancer develop recurrent disease within 2 years. In pancreatic cancer (PC), where only $10 \%-15 \%$ of tumours are considered resectable, the local recurrence rate ranges from $10 \%$ to $40 \%$ and distant recurrence is as high as $88 \% .^{14}$

There is evidence that variability exists in the management and outcomes of UGI cancers. For example, not all patients are presented to a multidisciplinary team meeting ${ }^{15}$; there are disparities in the utilisation of surgical resection and associated disease-specific survival based on where patients live ${ }^{16}$; there is wide variation in histopathological assessment of margins and the proportion that have clear margins ${ }^{14}$; the duration of surgery, postoperative complication rates and their management differ between public and private hospitals ${ }^{1718}$; administration of adjuvant chemotherapy or radiotherapy is variable, often due to morbidity associated with postoperative complications ${ }^{19}$; and the 30-day postoperative mortality is lower in hospitals performing more resections each year. ${ }^{20} 21$ Patients with UGI cancers have significant unmet needs pertaining to quality of life, finance, relationships and family or caregiver distress; these are often exacerbated by a lack of understanding of the health system. ${ }^{22}{ }^{23}$ In PC, over $50 \%$ of participants $(n=136)$ in an Australian-based study reported moderate to high unmet physical or psychological needs. ${ }^{24}$
Measuring quality of care with clinical quality registries (CQRs)

To identify, understand and reduce unwarranted clinical variation and ensure that all patients receive optimal care, it is important to collect high-quality disease-specific data. CQRs support continuous improvements in patient outcomes by monitoring quality of care and providing risk-adjusted feedback to the relevant clinical community. These data describe patterns of treatment in order to identify variation and can provide a framework for research. ${ }^{25}$ Successful implementation of CQRs has been achieved in a range of disciplines include trauma, cardiac, transplant and bariatric surgery, ${ }^{26}$ joint replacement ${ }^{27}$ and cancer care (eg, prostate) ${ }^{28}$

The Australian Commission on Safety and Quality in Health Care (ACSQHC) supports the development of CQRs in Australia through the provision of the national framework for CQRs. ${ }^{29}$ The framework details the necessary principles, guidelines and standards for best practice design, build, operation and security of CQRs. A recent evaluation of the cost-effectiveness of CQRs determined that when funded sufficiently with robust operating procedures, CQRs provide a substantial return on investment. ${ }^{30}$ In prioritising the development of CQRs in Australia, the ACSQHC ranked the development of registries for high-burden cancers only behind those monitoring ischaemic heart disease and musculoskeletal disorders. ${ }^{31}$ PC is ranked fourth as a high-burden cancer in terms of its impact on disability-adjusted life years behind lung, bowel and breast cancer. ${ }^{32}$ It was predicted to be the third leading cause of cancer deaths in the USA in 2018 and by 2030 is predicted to be the second most common cause of cancer associated mortality. ${ }^{2}$

Although a number of generic population-based cancer registries exist, there are no CQRs specific to the five aforementioned UGI cancers. Disease-specific registries $^{33} 34$ and audit databases ${ }^{35}$ provide much needed evidence about the management of patients with these cancers. However, little prospective data have been published from multi-institution databases and/or registries regarding the quality of UGI cancer care across the disease trajectory.

\section{Rationale for the Upper Gastrointestinal Cancer Registry (UGICR)}

Improvements in cancer outcomes for patients with UGI cancer will understandably come through establishment of models of care that are informed by close attention to clinical and patient-reported quality measures and standardisation of treatment that comply with agreed best practice. Given the lack of Australian population-level data regarding patient outcomes from UGI cancers, it was considered that a registry established to monitor treatment and outcomes of patients with cancers arising in the oesophagus, stomach, pancreas, liver and biliary system will improve management of these diseases. Furthermore, while detailed guidelines exist for each of these cancers, 


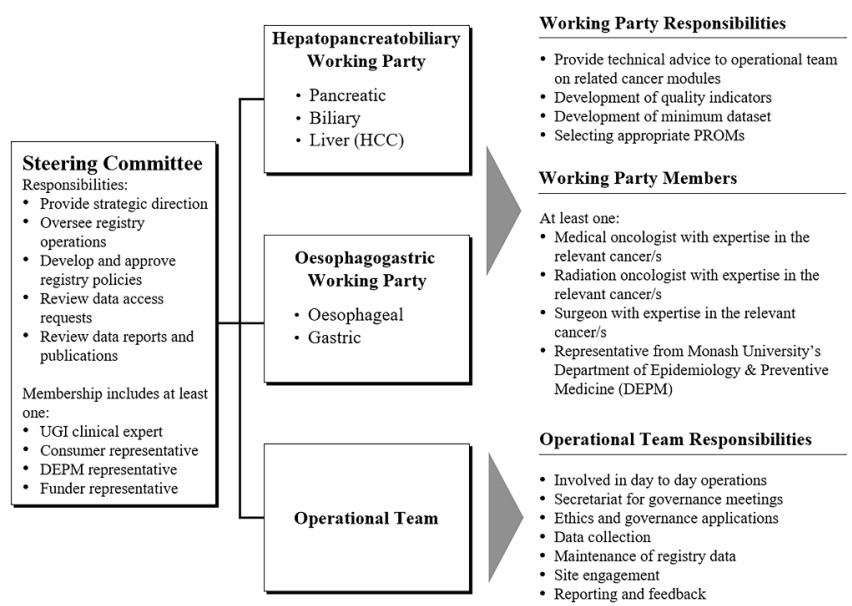

Figure 1 UGICR governance structure. HCC, hepatocellular carcinoma; PROMs, patient reported outcome measures; UGI, upper gastrointestinal.

gaps remain regarding optimal care and management of these patient groups. ${ }^{4-836}$

The UGICR is a CQR established with the aims to:

1. Assess patterns of care and identify variations in clinical and patient reported outcomes.

2. Benchmark performance and provide feedback to service providers using a targeted quality improvement approach to drive improvements in current practice.

3. Provide confidence to public, clinician and wider stakeholders on the delivery of high-quality service.

4. Advance knowledge of best treatment protocols by facilitating future clinical, health service, psychosocial and biomedical research.

\section{COHORT DESCRIPTION \\ Overview}

The UGICR is a multicentre, population-based, non-interventional prospective cohort study.

It was established in 2015 in Victoria and has since expanded to the state of New South Wales, Australia.

\section{Governance}

The UGICR is governed by a Steering Committee and, currently, two clinical working parties with the responsibility of each outlined in figure 1 . The Steering Committee performs in accordance with the Australian Framework for CQRs. ${ }^{29}$

A central research team provides operational oversights. A principal investigator at each participating hospital is responsible for ensuring that research activities undertaken at their site are conducted in accordance with the human research ethics committee (HREC) approval, the research protocol, site registry agreements and related policy documentation. At each site, patients are identified for recruitment and data collection occurs.

\section{Registry design}

The UGICR has a multimodular design with pancreatic, oesophagogastric (OG), liver and biliary cancer modules.

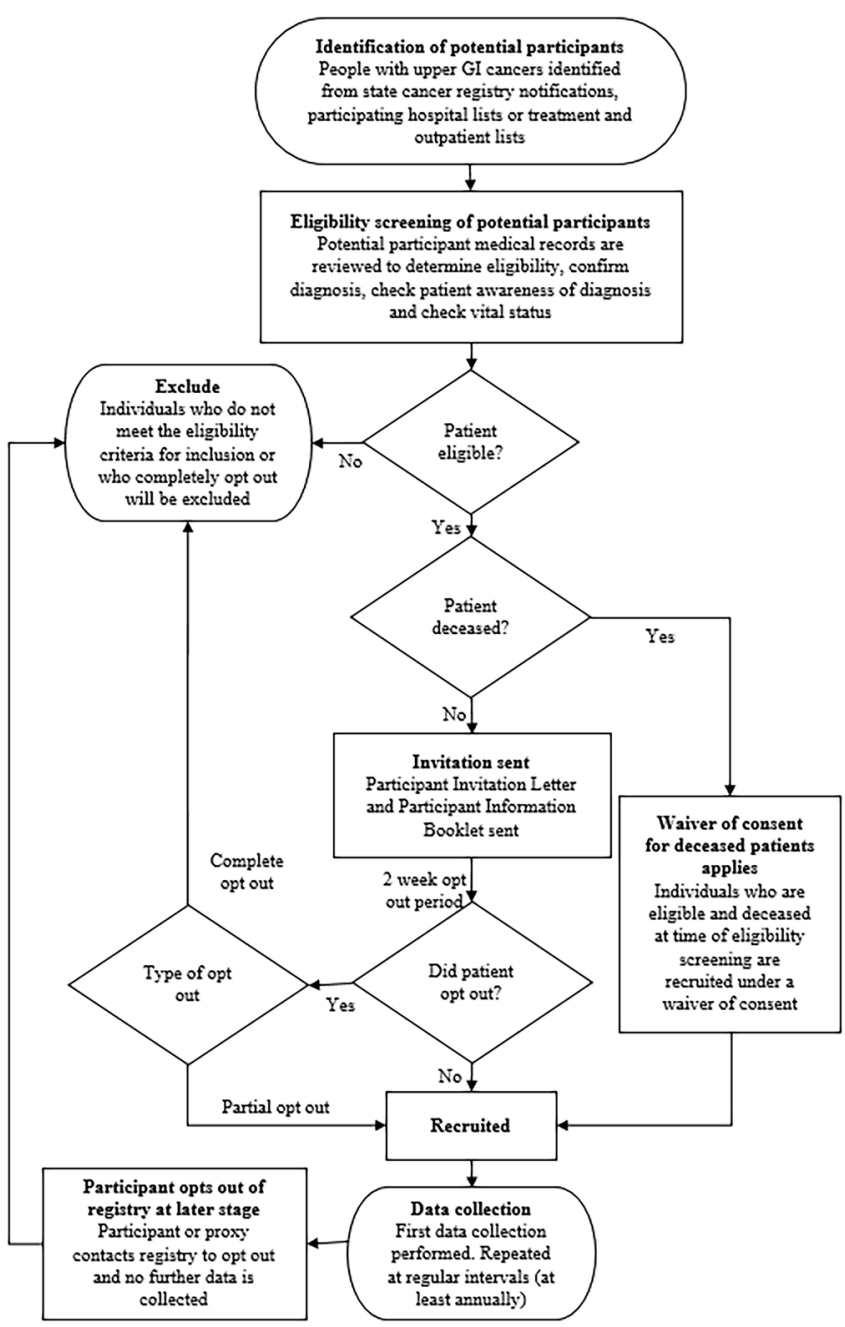

Figure 2 Registry recruitment schema. Gl, gastrointestinal.

Data are entered into Research Electronic Data Capture (REDCap), a secure web-based application, hosted and managed by Helix (Monash University). ${ }^{37}$ The registry was developed in REDCap, and all data are held securely on a Monash University server that has been accredited under the information security standard ISO27001. ${ }^{38}$

\section{Participant recruitment and consent}

The full recruitment schema is outlined in figure 2. Eligible patients are identified within each jurisdiction through state-based cancer registries or by individual health services. Eligibility criteria are listed in table 1 . The UGICR uses an opt-out approach to minimise selection bias. ${ }^{39}$

Eligible participants are mailed an introductory letter explaining the study and an information booklet outlining details of the registry, its purpose, possible outcomes of the research and the opt-out process. Participants are given 2 weeks to opt out of the registry before their participation is assumed, after which we commence collection of clinical and personal data covering diagnosis to end-of-life care. Patients can withdraw their consent from participation in the registry at any point by telephoning or emailing the UGICR office, as outlined in the participant information booklet. A waiver of consent applies 
Table 1 Eligibility criteria

\section{All modules}

Inclusion
with some limited exclusions specified in each module (see below).
2. Patient has been assessed or received care at a participating public or private hospital or private
clinician rooms.
3. Patient is 18 years of age or older at time of diagnosis.
4. Patient has a diagnosis date on or after 1 January 2016 (apart from one centre that commenced
recruitment in November 2015).

\begin{tabular}{|c|c|c|c|}
\hline \multicolumn{4}{|c|}{ Module specific } \\
\hline Modules & & Tumour sites & Tumour cell types \\
\hline \multirow[t]{2}{*}{ Pancreatic } & Inclusion & $\begin{array}{l}\text { Pancreas. } \\
\text { Periampullary region } \\
\text { Ampulla of Vater. } \\
\text { Biliary origin. } \\
\text { Intestinal origin. } \\
\text { Distal bile duct. }\end{array}$ & $\begin{array}{l}\text { Ductal adenocarcinoma. } \\
\text { Cholangiocarcinoma. } \\
\text { Acinar cell carcinoma. } \\
\text { Acinar cell cystadenocarcinoma. } \\
\text { IPMN (invasive). } \\
\text { Pancreatoblastoma. } \\
\text { Serous cystadenocarcinoma. }\end{array}$ \\
\hline & Exclusion & Non-distal bile duct & $\begin{array}{l}\text { Neuroendocrine neoplasms. } \\
\text { Premalignant lesions. } \\
\text { Mesenchymal tumours. } \\
\text { Solid pseudopapilliary carcinoma. } \\
\text { IPMN (non-invasive). }\end{array}$ \\
\hline \multirow[t]{2}{*}{ Oesophagogastric } & Inclusion & $\begin{array}{l}\text { Oesophagus (lower two-thirds). } \\
\text { Gastro-oesophageal junction. } \\
\text { Stomach. }\end{array}$ & $\begin{array}{l}\text { Carcinoma } \\
\text { Adenocarcinoma. } \\
\text { Squamous cell carcinoma. } \\
\text { Other subtypes. }\end{array}$ \\
\hline & Exclusion & Upper third of oesophagus. & $\begin{array}{l}\text { Neuroendocrine neoplasms. } \\
\text { Lymphomas. } \\
\text { Mesenchymal tumours. }\end{array}$ \\
\hline \multirow[t]{2}{*}{ Biliary } & Inclusion & $\begin{array}{l}\text { Perihilar (hilar) bile duct. } \\
\text { Intrahepatic bile duct. } \\
\text { Gall bladder. }\end{array}$ & $\begin{array}{l}\text { Carcinoma. } \\
\text { Cholangiocarcinoma. } \\
\text { Adenosquamous carcinoma. } \\
\text { Squamous cell carcinoma. } \\
\text { Cholangiosarcoma. }\end{array}$ \\
\hline & Exclusion & Distal bile duct. & $\begin{array}{l}\text { Neuroendocrine neoplasms. } \\
\text { Mesenchymal tumours. }\end{array}$ \\
\hline Liver $^{*}$ & $\begin{array}{l}\text { Inclusion } \\
\text { Exclusion }\end{array}$ & $\begin{array}{l}\text { Liver. } \\
\text { Intrahepatic bile duct. }\end{array}$ & $\begin{array}{l}\text { Hepatocellular carcinoma. } \\
\text { Cholangiocarcinoma. } \\
\text { Mesenchymal tumours. } \\
\text { Germ cell tumours. } \\
\text { Lymphomas. }\end{array}$ \\
\hline
\end{tabular}

*Liver module eligibility criteria still to be finalised.

IPMN, intraductal papillary mucinous neoplasm.

where patients deemed eligible require an interpreter, have significant cognitive impairment or where there is evidence that the patient is deceased.

\section{FINDINGS TO DATE}

\section{Data set}

The first module developed was the PC module, which began with a pilot phase of approximately 1 year, during which we collected data for a provisional set of quality indicators in three Victorian sites from 2016 to 2017. The second module developed using a similar pilot phase was the OG module. Subsequently, we used a formal modified Delphi consensus process to establish a core set of quality indicators for PC. This process involved 19 PC care experts from three states in Australia. A detailed description of the methods of the modified Delphi process and the selected indicators has been published separately. ${ }^{40}$ In addition, a review was undertaken of the Australian Optimal Care Pathways (OCP) for $\mathrm{PC}^{41}$ and $\mathrm{OGC}^{42}$ to ensure that indicators are aligned with the seven themes described in the OCP (prevention and early detection; presentation, initial investigations and referral; diagnosis, 
Table 2 PC Optimal Care Pathway (OCP) mapped to modified Delphi quality indicators

\section{PC OCP}

Step 1: Prevention and early detection

Step 2: Presentation, initial investigations and referral

\section{OCP elements}

1.1 Prevention.

1.2 Risk factors.

1.3 Early detection.

2.1 Signs and symptoms. 2.2 Assessments by general practitioner or medical practitioner. 2.3 Referral.

$2.4,3.5,4.6,5.4,6.6$ and 7.3

Support and communication

$\begin{array}{ll}\text { Step 3: Diagnosis, assessment } & \text { 3.1 Diagnostic workup. } \\ \text { and treatment planning } & \text { 3.2 Staging. } \\ & \text { 3.3 Treatment planning. }\end{array}$

3.4, 4.4, 5.3, 6.5 and 7.2 Research and clinical trials

3.1 and 3.2

Timeframe

Step 4: Treatment

Mapped quality indicators from modified Delphi consensus $^{40}$

Nil

Documented baseline CA19-9 level before treatment.

- Documented ECOG and/or ASA at presentation.

- Time from referral to definitive treatment within 60 days.

Nil

\subsubsection{Chemotherapy or} chemoradiation.

\section{2 .2 and 4.3}

Treatment of unresectable PC/ palliative care.
- Documented pancreatic protocol CT or MRI scan for diagnosis and/or staging.

- Operability of tumour is clearly defined and documented as either operable/resectable, borderline resectable, locally advanced (unresectable) or metastatic (unresectable).

- Disease management for all patients discussed at an MDT meeting.

- Number of patients included in a clinical trial.

- Time from referral to definitive treatment within 60 days.

Nil

- All patients who did not undergo surgery should have a valid reason documented.

- Number of patients undergoing PC surgery in a level 1-4 hospital.

- Adjuvant chemotherapy administered following surgery or a reason documented for not undergoing treatment.

- Chemotherapy \pm chemoradiation offered to patients with locally advanced disease, or a reason documented for not undergoing treatment.

- Number of patients who saw a medical or radiation oncologist or a reason documented for not doing so.

Nil

All patients having completed treatment followed up by a specialist every 3-6 months for up to 2 years. and recovery

Step 6: Managing recurrent, residual and metastatic disease

\subsection{Comp
therapies.}

\subsection{Survivorship}

5.2 Post-treatment care planning

\subsection{Signs and symptoms of} recurrent, residual or metastatic disease.

Step 7: End-of-life-care

\subsection{Palliative care. \\ 7.1 Multidisciplinary palliative care.}

Some elements in each step of the pathway are overlapping. Elements 6.2 and 6.3 readdress steps 3 and 4 . Please note: the purpose of this document is to provide a broad overview of the areas within the OCP that the developed PC quality indicators measure. Only the key indicators that map to the elements are listed.

ASA, American Society of Anesthesiologists (performance status); ECOG, Eastern Cooperative Oncology Group (performance status); MDT, Multidisciplinary Team.

staging and treatment planning; treatment; care after initial treatment and recovery; managing recurrent, residual or metastatic disease; and end-of-life care). An outline of this process for PC is provided in table 2. There are currently no clinical quality indicators in the UGICR that measure care for the prevention and early detection 
of PC. However, the UGICR is participating in a collaborative project, Symptom-UGI: Upper Gastrointestinal Cancer Symptom Study, to map the patient pathways from onset of symptoms to cancer diagnosis. Details of this study can be found within the UGICR website (https:// ugicr.org.au/associated-studies/).

The minimum data set was established to enable quality indicators to be calculated. Data items and definitions were aligned with national specifications where appropriate, and a comprehensive data dictionary was developed for each module. The core data items are outlined in table 3.

The OGG module has been developed by the OGC working party following a literature review, and a consensus method was used to agree on the quality indicator set. The registry has future plans to begin the collection of patient-reported outcomes (PROs) and patient-reported experiences (PREs) to provide valuable patient perspectives. As an initial step, a systematic review evaluating patient-reported outcome measures (PROMs) in PC has been undertaken by the UGICR team to define which PROMs are most appropriate for this group of patients.

\section{Data collection}

If the participant has not opted out of the registry, data collectors abstract diagnosis, surgical, pathology and treatment data directly from the participant's electronic and/or hard copy medical records from participating sites or from clinician rooms. Data collection begins close to the time of recruitment with at least annual follow-up until end of life.

\section{Results from the pilot studies from the PC and OGC modules}

The results of the pilot phase for both PC and OGC modules are displayed in table 4 . Of the 123 participants eligible for the PC module and 189 for the OGC module, $8(6.5 \%)$ and $9(4.8 \%)$ opted out of the registry, respectively. Clinical stage at diagnosis was not well documented in both the PC module $(\mathrm{n}=80,70 \%)$ and OGC cancer module $(n=82,46 \%)$ and is an area for future quality improvement. Around 20\% of the pancreatic cohort received surgery as first treatment, which is broadly representative of surgical treatment in patients with $\mathrm{PC}^{43}$ Furthermore, 73 participants in the $\mathrm{PC}$ and 94 participants in the OGC module had documented reasons for no surgery. The pilot results for both modules identified areas for improving data completeness, definitions, items and structure of data collection forms. Following the pilot phase, the registry focused on improving these areas before expanding to other participating hospitals.

\section{Population coverage}

Population coverage in Victoria is based on data from the Victorian Cancer Registry. The population coverage in the pilot phase was 19\% for the PC module and $11 \%$ for the OGC module. Current coverage is $73 \%$ for PC and $55 \%$ for the OGC module. In New South Wales, data are currently only being collected on the PC module with an estimated population coverage of $55 \%$.

\section{Reporting}

The registry will produce risk-adjusted benchmarked reports that will feed back deidentified data to participating sites on the associated quality indicators. To provide fair and meaningful benchmarked reports, we have undertaken a review of risk models to identify demographic and baseline clinical variables (focusing on those over which clinicians have no control, for example, age, sex and disease stage) that predict patient outcomes for the purposes of risk adjustment. The data from the registry will also permit validation of current predictive risk models and enable further refinement of these tools. Publicly available annual reports that provide an overview of quality of care and the registry's activities will be published. A UGICR website (https://ugicr.org.au/) has been developed to provide information about the registry to patients, clinicians and other stakeholders. This will be updated to include results as they become available.

\section{STRENGTHS AND LIMITATIONS}

The UGICR is Australia's first UGI cancer CQR. The aims of the registry are to monitor quality of care, benchmark clinical and patient-reported outcomes against best practice and provide high-quality population-based data for clinical research. Registries such as the UGICR provide much needed real-world evidence outside the context of randomised control trials about disease epidemiology, treatment patterns, burden of illness, survival outcomes, clinical variation and treatment safety. ${ }^{44}$

In recent decades, there has been increasing integration of PROMs into cancer registries to collect outcomes such as overall quality of life, functional and psychosocial wellbeing, lifestyle behaviours and supportive care needs. ${ }^{45}$ Clinicians and patients may place different emphasis on symptom impacts and expectations from their treatment. ${ }^{46}$ The collection of PROMs is an important step in understanding patients' experience of their symptoms and management and the impact of the disease and its treatment on their quality of life. The UGICR will determine and integrate the most relevant PROMs for each UGI cancer type following thorough examination of the literature.

Through the accumulation of significant and consistent data on UGI cancers, the registry will assess how clinical management compares with best practice and communicate this to clinicians through the PIs or relevant hospital departments. Furthermore, the UGICR provides a platform for longer term clinical follow-up, randomised clinical trials and substudies exploring treatment outcomes and linking outcomes to tumour tissue characteristics.

An important consideration is the maturity of each module before useful quality indicator reports can be provided to participating hospitals, as some UGI cancers have a relatively low incidence in comparison with other 

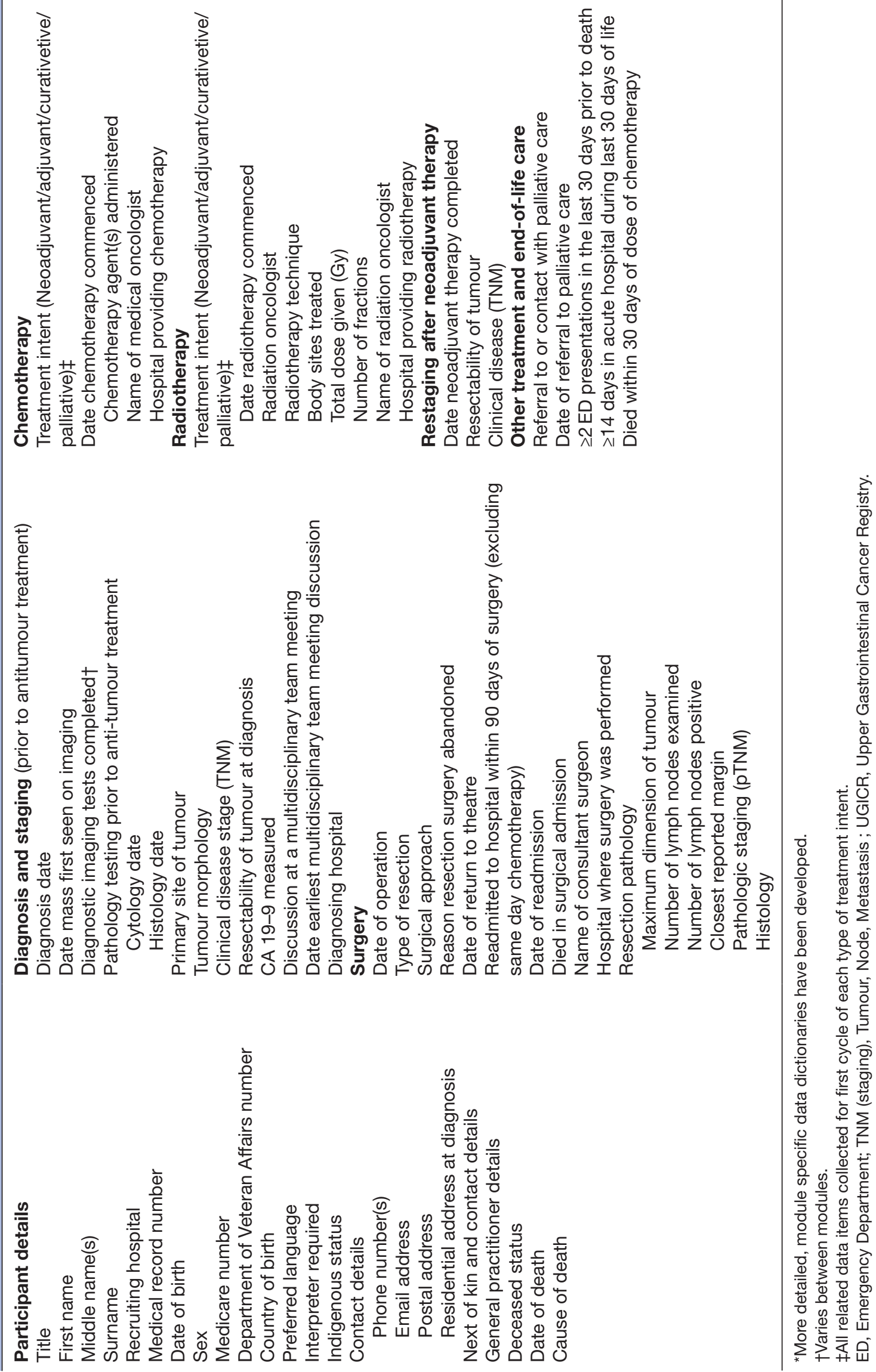
Open access

Table 4 PC and OGC module data from pilot data collection

\begin{tabular}{|c|c|c|}
\hline & PC module & OGC module \\
\hline Variable & $\mathrm{n}(\%)$ & $n(\%)$ \\
\hline Recruited & 115 & 180 \\
\hline Recruited via invitation letter & $88(76.5)$ & $120(66.7)$ \\
\hline $\begin{array}{l}\text { Recruited via waiver of consent } \\
\text { (deceased) }\end{array}$ & $27(23.5)$ & $60(33.3)$ \\
\hline \multicolumn{3}{|l|}{ Sex } \\
\hline Male & $56(48.7)$ & $132(73.3)$ \\
\hline Female & $59(51.3)$ & $48(26.7)$ \\
\hline \multicolumn{3}{|l|}{ Age at diagnosis (years) } \\
\hline$<50$ & $6(5.2)$ & $11(6.1)$ \\
\hline $50-59$ & $14(12.2)$ & $22(12.2)$ \\
\hline $60-69$ & $30(26.1)$ & $54(30.0)$ \\
\hline $70-79$ & $38(33.0)$ & $54(30.0)$ \\
\hline$\geq 80$ & $22(19.1)$ & $33(18.3)$ \\
\hline Missing & $5(4.3)$ & $6(3.3)$ \\
\hline \multicolumn{3}{|l|}{ Resectability at diagnosis } \\
\hline Resectable & $25(21.7)$ & $58(32.2)$ \\
\hline Borderline resectable & $3(2.6)$ & $11(6.1)$ \\
\hline Unresectable & $67(58.3)$ & $64(35.6)$ \\
\hline Locally advanced $(L A)$ & $24(20.9)$ & $6(3.3)$ \\
\hline Metastatic (Mets) & $43(37.4)$ & $58(32.2)$ \\
\hline Not documented & $14(12.2)$ & - \\
\hline Unknown & - & $41(22.8)$ \\
\hline Missing & $6(5.2)$ & $6(3.3)$ \\
\hline \multicolumn{3}{|l|}{ Clinical stage at diagnosis } \\
\hline | or II & $5(4.3)$ & $33(18.3)$ \\
\hline III & - & 7 (3.9) \\
\hline IV & $18(15.7)$ & $50(27.8)$ \\
\hline Complete $\mathrm{TNM}^{\star}$ not documented & $80(69.6)$ & $82(45.6)$ \\
\hline Missing & $12(10.4)$ & $8(4.4)$ \\
\hline \multicolumn{3}{|l|}{ First treatment } \\
\hline Neoadjuvant therapy & $4(3.5)$ & $60(33.3)$ \\
\hline $\begin{array}{l}\text { Attempted or completed resection } \\
\text { surgery }\end{array}$ & $27(23.5)$ & $13(7.2)$ \\
\hline Curative intent ChemoTx and/or RT & - & 7 (3.9) \\
\hline Palliative intent ChemoTx and/or RT & $37(32.2)$ & $55(30.6)$ \\
\hline No treatment & $29(25.2)$ & $23(12.8)$ \\
\hline Unknown & - & $16(8.9)$ \\
\hline Missing & $18(15.7)$ & $6(3.3)$ \\
\hline \multicolumn{3}{|l|}{ Reasons for no surgery† } \\
\hline LA or Mets & 62 & 60 \\
\hline Advanced age & 1 & 6 \\
\hline Comorbidities & 7 & 9 \\
\hline Patient declined & 1 & 12 \\
\hline Patient died prior to surgery & 0 & 7 \\
\hline
\end{tabular}

Continued 
Table 4 Continued

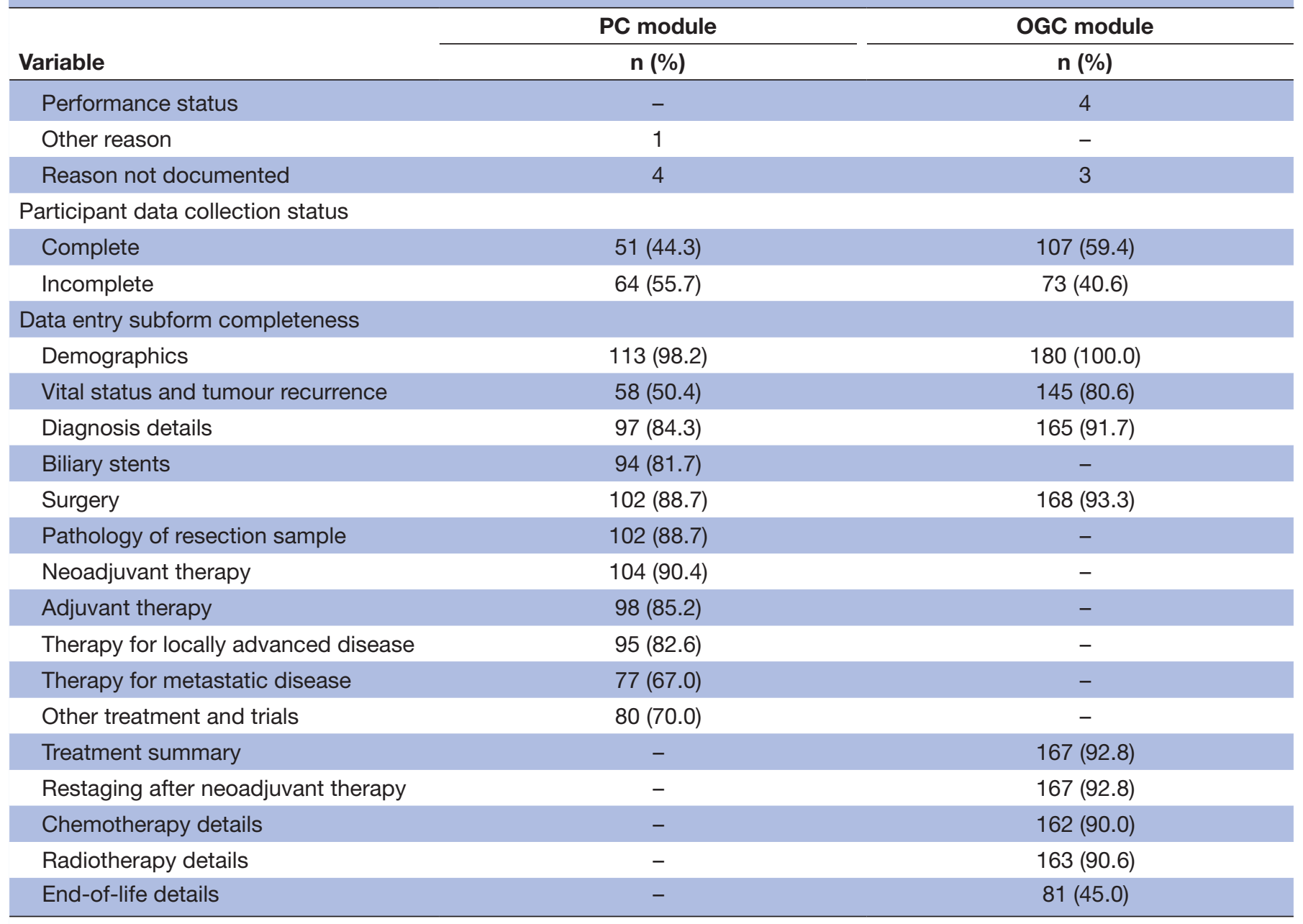

${ }^{*}$ TNM system of classification of cancer.

†Reason for no surgery: participants may have more than one reason documented.

ChemoTX, chemotherapy; RT, radiotherapy.

cancers. ${ }^{1}$ The working groups in collaboration with statisticians will determine an analysis plan for each indicator with due consideration to data completeness and risk adjustment methods.

\section{Identified challenges}

The UGICR has faced some key challenges affecting its establishment and implementation. The introduction of the National Mutual Acceptance (NMA) scheme has significantly streamlined the ethics process for all public hospitals in Australia, except in the Northern Territory, making the process to gain approval for CQRs more manageable. However, obtaining governance approval at each site continues to be both labour intensive and time consuming. ${ }^{47} 48$ Furthermore, separate HREC approval is frequently required to access data from private hospitals and clinics.

Funding is another challenge faced by CQRs. As with many healthcare initiatives, the financial burden can be a major impediment. ${ }^{25}$ Data from CQRs are held in positive regard by clinicians, health managers and government.
However, further funding will be required to progress national rollout of the registry.

Other identified barriers include reluctance of some healthcare providers to supply source data, and poor interoperability between clinical information systems leading to duplication of data entry. Where data are of high quality, such as for diagnosis and procedure codes, administrative data is appropriate, but there are limited data for comorbidities and risk factors. ${ }^{49}$ While automation of data collection from existing data sources would be ideal, this is hampered by inconsistent documentation and a lack of standardisation. ${ }^{50}$

\section{Collaboration}

The UGICR aims to capture whole of population, realworld data that monitors and aspires to improve the quality of care provided to patients with UGI cancers. The registry is currently recruiting hospitals to increase population capture and selecting the most relevant instruments for measuring PROs and PREs for inclusion in each module. The biliary module is entering its pilot 
phase, and the liver module is to be developed. Monash University is the UGICR's data custodian and is accountable for the privacy, security and integrity of patient information held within the registry. Participating sites can request a copy of their own patient-level data. Researchers may access registry data following a formal submission to the UGICR data custodian and approval by the UGICR Steering Committee. They are required to complete a request form detailing their research aims and methods, potential impact on healthcare, and provide evidence relevant HREC approval before deidentified data will be released. The registry will harness new opportunities for data linkage with technologies such as the electronic medical records and collaborate with existing data repositories (eg, biomedical) to evolve and fulfil its aim of providing quality evidence.

\section{Author affiliations}

${ }^{1}$ Public Health and Preventative Medicine, Monash University, Melbourne, Victoria, Australia

${ }^{2}$ Department of Surgery, Monash University, Melbourne, Victoria, Australia

${ }^{3}$ Monash Health, Melbourne, Victoria, Australia

${ }^{4}$ Alfred Health, Melbourne, Victoria, Australia

${ }^{5}$ Royal Prince Alfred Hospital, Camperdown, New South Wales, Australia

${ }^{6}$ Western Health, Melbourne, Victoria, Australia

${ }^{7}$ Peter MacCallum Cancer Centre, Melbourne, Victoria, Australia

${ }^{8}$ Department of Surgery, Austin Health, University of Melbourne, Melbourne, Victoria, Australia

${ }^{9}$ Austin Health, Melbourne, Victoria, Australia

${ }^{10}$ Peninsula Health, Melbourne, Victoria, Australia

${ }^{11}$ Nelune Comprehensive Cancer Centre, Prince of Wales, Randwick, New South Wales, Australia

${ }^{12}$ St Vincent's Hospital, Melbourne, Victoria, Australia

${ }^{13}$ Royal Melbourne Hospital, Melbourne, Victoria, Australia

${ }^{14}$ School of Medicine, Western Sydney University, Penrith South, New South Wales, Australia

${ }^{15}$ Population Health Division, QIMR Berghofer Medical Research Institute, Herston, Queensland, Australia

${ }^{16}$ Cabrini Health, Malvern, Victoria, Australia

Acknowledgements The authors first and foremost gratefully acknowledge and thank our participants. We would also like to thank our consumer representatives, Jan Gibson and David Attwood, for their ongoing support and contribution to the registry. The authors would also like to acknowledge the participating hospitals, site investigators and Victorian Cancer Registry for providing ongoing data to the Upper Gastrointestinal Cancer Registry (UGICR).

Contributors ADM and JFH are joint first authors on this manuscript. SME, WAB, DGC, CHCP, JGK, LRL, TL, JJM, MN and JZ are part of the UGICR Steering Committee. SME, LI, WAB, DGC, CHCP, JGK, LRL, TL, MN, AA, PRB, PAC, JC, CD, PE, DG, AH, MWH, BPFK, NM, MM, REN, JP, IWTP, MS, JS, PPT and JZ are part of the working parties. RS and JFH developed the registry protocol in consultation with the UGICR Steering Committee and working parties. All authors reviewed and provided feedback on the drafts of the manuscript and approved the final version.

Funding The authors gratefully acknowledge the Victorian Government, Pancare Foundation, Specialised Therapeutics Australia, Servier Australia, Eli Lilly Australia, and the Australian National Health and Medical Research Council for the Pancreatic Cancer Registry for Quality Improvement grant (grant number APP1125395). The Victorian Government and Pancare Foundation were involved in the design of the study through steering committee representation.

Competing interests None declared.

Patient consent for publication Not required.

Ethics approval This project has received human research ethics committee (HREC) approval from the following HRECs: Monash Health (Ref: 15482A) under the National Mutual Acceptance scheme (HREC/15/MonH/134); Cancer Council Victoria (HREC 1611); Epworth HealthCare (EH2017-227), Aboriginal Health \&
Medical Research Council (1387/18) and is registered with Monash University (CF16/119-2016000051).

Provenance and peer review Not commissioned; externally peer reviewed.

Open access This is an open access article distributed in accordance with the Creative Commons Attribution Non Commercial (CC BY-NC 4.0) license, which permits others to distribute, remix, adapt, build upon this work non-commercially, and license their derivative works on different terms, provided the original work is properly cited, appropriate credit is given, any changes made indicated, and the use is non-commercial. See: http://creativecommons.org/licenses/by-nc/4.0/.

\section{ORCID iDs}

Ashika D Maharaj http://orcid.org/0000-0002-4725-613X

Sue M Evans http://orcid.org/0000-0003-2962-8400

Daniel G Croagh http://orcid.org/0000-0002-6430-6741

Jennifer Philip http://orcid.org/0000-0002-3312-0645

\section{REFERENCES}

1. Australian Institute of Health and Welfare. Cancer in Australia 2019. Canberra: AlHW, 2019. 205p. Cancer series no.119.

2. Siegel RL, Miller KD, Jemal A. Cancer statistics, 2017. CA Cancer J Clin $2017 ; ; 67: 7-30$. Jan.

3. Rugge M, Fassan M, Graham DY, et al. Epidemiology of Gastric Cancer [internet. Switzerland: Springer, 2015: p23-34.

4. Ducreux M, Cuhna AS, Caramella C, et al. Cancer of the pancreas: ESMO clinical practice guidelines for diagnosis, treatment and follow-up. Ann Oncol 2015;26 Suppl 5(suppl 5):v56-68.

5. Vogel A, Cervantes A, Chau I, et al. Hepatocellular carcinoma: ESMO clinical practice guidelines for diagnosis, treatment and follow-up. Ann Oncol 2018;29(Suppl 4):iv238-55.

6. Lordick F, Mariette C, Haustermans K, et al. Oesophageal cancer: ESMO clinical practice guidelines for diagnosis, treatment and follow-up. Ann Oncol 2016;27(suppl 5):v50-7.

7. Smyth EC, Verheij M, Allum W, et al. Gastric cancer: ESMO clinical practice guidelines for diagnosis, treatment and follow-up. Ann Oncol 2016;27(suppl 5):v38-49.

8. Valle JW, Borbath I, Khan SA, et al. Biliary cancer: ESMO clinical practice guidelines for diagnosis, treatment and follow-up†. Annal Oncol 2016;27(suppl_5):v28-37.

9. Whistance RN, Blazeby JM. Systematic review: quality of life after treatment for upper gastrointestinal cancer. Curr Opin Support Palliat Care 2011;5:37-46.

10. Davis SS, Babidge WJ, Kiermeier A, et al. Perioperative mortality following oesophagectomy and pancreaticoduodenectomy in Australia. World J Surg 2018;42:742-8.

11. Zhou J, Hiki N, Mine S, et al. Role of prealbumin as a powerful and simple index for predicting postoperative complications after gastric cancer surgery. Ann Surg Oncol 2017;24:510-7.

12. Spolverato G, Ejaz A, Kim Y, et al. Rates and patterns of recurrence after curative intent resection for gastric cancer: a United States multi-institutional analysis. J Am Coll Surg 2014;219:664-75.

13. Knight WRC, Zylstra J, Van Hemelrijck M, et al. Patterns of recurrence in oesophageal cancer following oesophagectomy in the era of neoadjuvant chemotherapy. BJS Open 2017;1:182-90.

14. Chandrasegaram MD, Goldstein D, Simes J, et al. Meta-Analysis of radical resection rates and margin assessment in pancreatic cancer. Br J Surg 2015;102:1459-72.

15. Brauer DG, Strand MS, Sanford DE, et al. Utility of a multidisciplinary tumor board in the management of pancreatic and upper gastrointestinal diseases: an observational study. HPB 2017;19:133-9.

16. Shapiro $M$, Chen $Q$, Huang $Q$, et al. Associations of socioeconomic variables with resection, stage, and survival in patients with earlystage pancreatic cancer. JAMA Surg 2016;151:338-45.

17. Chua TC, Mittal A, Nahm C, et al. Pancreatoduodenectomy in a public versus private teaching hospital is comparable with some minor variations. ANZ J Surg 2018:88:E526-E531.

18. Busweiler LA, Henneman D, Dikken JL, et al. Failure-To-Rescue in patients undergoing surgery for esophageal or gastric cancer. European Journal of Surgical Oncology 2017;43:1962-9.

19. Schouwenburg MG, Busweiler LAD, Beck N, et al. Hospital variation and the impact of postoperative complications on the use of perioperative chemo(radio)therapy in resectable gastric cancer. Results from the Dutch Upper GI Cancer Audit. Eur J Surg Oncol 2018;44:532-8. 
20. Dikken JL, van Sandick JW, Allum WH, et al. Differences in outcomes of oesophageal and gastric cancer surgery across Europe. Br J Surg 2013;100:83-94.

21. Skipworth RJE, Parks RW, Stephens NA, et al. The relationship between hospital volume and post-operative mortality rates for upper gastrointestinal cancer resections: Scotland 1982-2003. Eur J Surg Oncol 2010;36:141-7.

22. Otutaha B, Srinivasa S, Koea J. Patient information needs in upper gastrointestinal cancer: what patients and their families want to know. ANZ J Surg 2019;89:20-4.

23. Shaw J, Harrison J, Young J, et al. Coping with newly diagnosed upper gastrointestinal cancer: a longitudinal qualitative study of family caregivers' role perception and supportive care needs. Support Care Cancer 2013;21:749-56.

24. Beesley VL, Janda M, Goldstein D, et al. A tsunami of unmet needs: pancreatic and ampullary cancer patients' supportive care needs and use of community and allied health services. Psychooncology 2016;25:150-7.

25. Wilcox N, McNeil JJ. Clinical quality registries have the potential to drive improvements in the appropriateness of care. Med J Aust 2016;205:21-6.

26. Stey AM, Russell MM, Ko CY, et al. Clinical registries and quality measurement in surgery: a systematic review. Surgery 2015;157:381-95.

27. Owen DH, Russell NC, Smith PN, et al. An estimation of the incidence of squeaking and revision surgery for squeaking in ceramic-on-ceramic total hip replacement: a meta-analysis and report from the Australian orthopaedic association national joint registry. Bone Joint $J$ 2014;96-B:181-7.

28. Evans SM, Millar JL, Wood JM, et al. The prostate cancer registry: monitoring patterns and quality of care for men diagnosed with prostate cancer. BJU Int 2013;111:E158-E166.

29. Australian Commission on safety and quality in healthcare (ACSQHC). framework for Australian clinical quality registries. Australia 2014

30. Ahern S, Evans S, Hopper I, et al. Towards a strategy for clinical quality registries in Australia. Aust Heal Rev 2018.

31. Australian Commission on Safety and Quality in Healthcare. Prioritised list of clinical domains for clinical quality registry development: final report. Sydney: ACSQHC, 2016.

32. Australian Institute of Health and Welfare. Burden of cancer in Australia: Australian burden of disease study 2011. Canberra: AlHW, 2017: 145p.

33. Egawa $\mathrm{S}$, Toma $\mathrm{H}$, Ohigashi $\mathrm{H}$, et al. Japan pancreatic cancer registry; 30th year anniversary: Japan pancreas Society. Pancreas 2012;41:985-92.

34. de Steur WO, Henneman D, Allum WH, et al. Common data items in seven European oesophagogastric cancer surgery registries: towards a European upper Gi cancer audit (EURECCA upper Gi). Eur J Surg Oncol 2014;40:325-9.

35. Busweiler LAD, Jeremiasen M, Wijnhoven BPL, et al. International benchmarking in oesophageal and gastric cancer surgery. BJS Open 2019;3.
36. Te Riele W, van Tinteren H, van Sandick J. Centralization of upper gastrointestinal cancer care should be dictated by quality of care. Ann Surg Oncol 2018;25(Suppl 3):984-5.

37. Harris PA, Taylor R, Thielke R, et al. Research electronic data capture (REDCap)--a metadata-driven methodology and workflow process for providing translational research informatics support. J Biomed Inform 2009;42:377-81.

38. International Standards Organisation. ISO/IEC 27001 Information technology - Security techniques - Information security management systems - Requirements. ISO, 2005.

39. Tu JV, Willison DJ, Silver FL, et al. Impracticability of informed consent in the registry of the Canadian stroke network. $N$ Engl J Med 2004;350:1414-21.

40. Maharaj AD, loannou L, Croagh D, et al. Monitoring quality of care for patients with pancreatic cancer: a modified Delphi consensus. HPB (Oxford), 2018.

41. Cancer Council Australia. Optimal care pathway for people with pancreatic cancer, 2016. Available: https://www.cancer.org. $\mathrm{au} /$ content/ocp/health/optimal-care-pathway-for-people-withpancreatic-cancer-june-2016.pdf [Accessed cited 2018 Oct 20].

42. Cancer Council Australia. Optimal care pathway for people with oesophagogastric cancer, 2016. Available: https://www.cancer. org.au/content/ocp/health/optimal-care-pathway-for-people-withoesophagogastric-cancer-june-2016.pdf [Accessed 2018 Nov 18].

43. Siegel RL, Miller KD, Jemal A. Cancer statistics, 2018. CA Cancer J Clin 2018;68:7-30.

44. Berger ML, Sox H, Willke RJ, et al. Good practices for real-world data studies of treatment and/or comparative effectiveness: recommendations from the joint ISPOR-ISPE special Task force on real-world evidence in health care decision making. Pharmacoepidemiol Drug Saf 2017;26:1033-9.

45. Ashley L, Jones $\mathrm{H}$, Thomas J, et al. Integrating patient reported outcomes with clinical cancer registry data: a feasibility study of the electronic patient-reported outcomes from cancer survivors (ePOCS) system. J Med Internet Res 2013;15:e230-e.

46. Chassany O, Shaheen NJ, Karlsson M, et al. Systematic review: symptom assessment using patient-reported outcomes in gastroesophageal reflux disease and dyspepsia. Scand $J$ Gastroenterol 2012;47:1412-21.

47. Clay-Williams R, Taylor N, Braithwaite J. Potential solutions to improve the governance of multicentre health services research. Med J Aust 2018;208:152-4.

48. Brown WA, Smith BR, Boglis M, et al. Streamlining ethics review for multisite quality and safety initiatives: national bariatric surgery registry experience. Med J Aust 2016;205:200-1.

49. Alexander M, Evans SM, Wolfe R, et al. Risks of using medical record and administrative data for prognostic models. Med J Aust $2017 ; 207$

50. Gliklich RE DN, Leavy MB. Registries for Evaluating Patient Outcomes: A User's Guide[internet]. 3rd Ed. Rockville (MD): Agency for Healthcare Research and Quality (US), 2014. Apr. Available from. https://www.ncbi.nlm.nih.gov/books/NBK208616/ 